\title{
Application of Spectrophotometry and High Performance Liquid Chromatography for the Analysis of Bosentan in Pharmaceutical Dosage Form
}

\author{
PETIKAM LAVUDU ${ }^{1}$, AVULA PRAMEELA RANI ${ }^{2}$, \\ CHANDRA BALA SEKARAN ${ }^{3}$, A.RAMESH ${ }^{4}$ and A.ANIL KUMAR ${ }^{1}$
}

${ }^{1}$ Department of Pharmaceutical Biotechnology, Vishnu Institute of Pharmaceutical Education and Research, Narsapur, Andhra Pradesh- 502313, India

${ }^{2}$ University College of Pharmaceutical Sciences, Acharya Nagarjuna University, Guntur, Andhra Pradesh-522510, India

${ }^{3}$ Department of Basic sciences, Nri Institute of Technology, Pothavarappadu, Andhra Pradesh-520010, India

${ }^{4}$ Department of Pharmacology, Vishnu Institute of Pharmaceutical Education and Research, Narsapur, Andhra Pradesh- 502313, India

plavudu@yahoo.com

Received 6 May 2014 / Accepted 2 June 2014

\begin{abstract}
Three new spectrophotometric methods (A, B and C) and one new high performance liquid chromatography (HPLC) method (D) for the quantitative analysis of bosentan (BSN) in pharmaceutical dosage forms have been described. The method $\mathrm{A}$ involves the oxidation of bosentan with ammonium molybdate in acidic medium which results in a blue-colored product. The methods $\mathrm{B}$ and $\mathrm{C}$ are based on the formation of yellow colored ion-pair complexes with 2, 4-dinitrophenol and bromocresol green, respectively. In method D, the determination of bosentan was carried out on Agilent C18 column (150 $\mathrm{mm} \times 4.6 \mathrm{~mm}$ I.D., $5 \mu \mathrm{m})$ in isocratic mode with methanol and ammonium acetate buffer $(60: 40 \mathrm{v} / \mathrm{v})$ as mobile phase. The flow rate was $1.0 \mathrm{~mL} / \mathrm{min}$ and eluent was monitored at $227 \mathrm{~nm}$. The retention time of bosentan was $2.449 \mathrm{~min}$. Under the optimized experimental conditions, Beer's plot showed good correlation in the concentration ranges of 2-30, 5-30, 2.5-50 and 5-100 $\mu \mathrm{g} / \mathrm{mL}$ for methods $\mathrm{A}, \mathrm{B}$, $\mathrm{C}$ and $\mathrm{D}$ respectively. The methods were validated in accordance with the International Conference on Harmonization (ICH) guidelines. These methods were found to be sensitive, accurate, precise and robust and were successfully applied to the estimation of tablet dosage forms containing bosentan. There was no interference from the tablet excipients.
\end{abstract}

Keywords: Bosentan, Spectrophotometry, HPLC, Tablet dosage forms, Analysis

\section{Introduction}

Bosentan $(\mathrm{BSN})^{1-4}$, is an antihypertensive agent and non-peptide endothelin receptor antagonist used in the treatment of patients with pulmonary artery hypertension. BSN is 
approved by the Food and Drug Administration. Endothelin, a neurohormone, promote narrowing of the blood vessels and lead to high blood pressure. Bosentan exerts its activity by blocking the action of endothelin. Chemically, BSN is known as $N$-[6-(2Hydroxyethoxy)-5-(2-methoxyphenoxy)-2-pyrimidin-2-yl-pyrimidin-4-yl]-4-tert-butylbenzenesulfonamide (Figure1).<smiles>COc1ccccc1Oc1c(NS(=O)(=O)c2ccc(C(C)(C)C)cc2)nc(-c2ncccn2)nc1OCCO</smiles>

Figure 1. Structure of bosentan

Annapurna et al., Ashok Kumar et al. Kumar et al. and Narendra et al., reported UVspectrophotometric methods ${ }^{5-8}$, employing different solvents for the determination of BSN in pharmaceutical dosage forms. The literature survey showed that there were only few chromatographic methods for the determination of BSN. Khan et al,. ${ }^{9}$ and Jadhav et al., ${ }^{10}$, developed stability indicating HPLC method for the determination of related substances of BSN and degradation impurities in BSN, respectively. Lausecker et al., ${ }^{11-12}$, have reported two narrow-bore liquid chromatography with ion spray tandem mass spectrometric detection methods for the assay of BSN in various biological matrices and species.

The UV-spectrophotometric methods ${ }^{5-8}$ suffered from the lack of selectivity and sensitivity. The reported stability indicating HPLC methods ${ }^{9-10}$ are sensitive but suffered from disadvantages such as narrow range of linear response, more retention time and less precise. Although the LC/MS methods ${ }^{11-12}$ are sensitive, they are expensive and not easily manageable. LC/MS method employed the expensive mass detectors that are not available in most of the quality control laboratories and involved arduous extraction procedures. Further more, the stability indicating HPLC methods and LC/MS methods are not applied to pharmaceutical dosage forms.

Muralidharan and Kumar ${ }^{13}$, Reddy et $a l^{14}$ and Rao et al., ${ }^{15}$ reported HPLC with UV detection methods for the assay of BSN in bulk drug and pharmaceutical dosage forms. These methods ${ }^{13-15}$ suffers from drawbacks such as lack of sensitivity, less precise, narrow range of linear response, more retention time and longer runtime.

Therefore, the development of new simple, sensitive, rapid, cost effective and precise alternative spectrophotometric and HPLC methods for the determination of BSN in pharmaceutical dosage forms is needed. The present work describes the development and validation of three spectrophotometric methods (A, B and C) and one HPLC method (D), which is able to quantify BSN in pure and pharmaceutical dosage forms.

\section{Experimental}

All spectrophotometric measurements were carried out using an Elico (Hyderabad, India) double beam SL 159 digital spectrophotometer. The cells used for absorbance measurements were $1 \mathrm{~cm}$ matched quartz cells.

Chromatographic separation was achieved by using Shimadzu HPLC class VP series, (Shimadzu Corporation, Kyoto, Japan) high-performance liquid chromatographic system, variable wavelength programmable UV/Visible detector SPD-10A, LC-10 AT pump, SCL$10 \mathrm{~A}$ system controller and CTO-10 AS column oven. The chromatographic system utilizes a 
Shimadzu class VP series version 5.03 computer programs to control the hardware, acquire and store data. Agilent C18 column, $150 \mathrm{~mm} \times 4.6 \mathrm{~mm}$ I.D., $5 \mu \mathrm{m}$ particle size (Agilent Technologies, Inc., Waldbronn, Germany) was used as the stationary phase, which is maintained at room temperature.

Other instruments such as water bath (Kemi KWB 220 model, Ernakulam, India), pH meter (LI 120 model, Elico pH meter, Hyderabad, India) and electronic weighing balance (model BL 220 H, Shimazdu, Tokyo, Japan) were also used.

\section{Chemicals and reagents}

All chemicals used in methods A, B and C (spectrophotometry) was of analytical reagent grade. For method A, 5\% aqueous solution of ammonium molybdate (AM) (Qualigens, Mumbai, India) and $2 \mathrm{M}$ hydrochloric acid $(\mathrm{HCl})(\mathrm{Sd}$ fine Chem Ltd, Mumbai, India) were prepared. $0.1 \%$ 2,4 Dintrophenol (DNP) (Sd fine Chem Ltd., Mumbai, India) in methanol (Merck, Hyderabad, India) and $0.07 \%$ bromocresol green (BCG) (Qualigens, Mumbai, India) in dichloromethane (Sd fine Chem Ltd., Mumbai, India) were prepared for methods B and C, respectively.

The solvents and chemicals used in the method D (HPLC) were of HPLC grade quality. Methanol, glacial acetic acid and ammonium acetate were purchased from Sd fine Chem Limited, Mumbai, India. Solutions were prepared with Milli-Q-water obtained from Merck Specialties Private Ltd, Hyderabad, India. The mobile phase used was prepared by mixing methanol and ammonium acetate buffer $(\mathrm{pH} \mathrm{4.5)}$ in the ratio 60:40. Ammonium acetate buffer ( $\mathrm{pH} 4.5$ ) was prepared by dissolving $30 \mathrm{~g}$ of ammonium acetate in $90 \mathrm{~mL}$ of water. The $\mathrm{pH}$ was adjusted to 4.5 with glacial acetic acid and volumed up to $100 \mathrm{~mL}$ with distilled water. The mobile phase was also used as diluent solution for the preparation of standard solutions in method $\mathrm{D}$. The mobile phase was degassed with a helium sparge for $15 \mathrm{~min}$ and filtered using $0.45 \mu \mathrm{m}$ membrane filter before use.

\section{Standard solutions}

Pharmaceutical grade BSN was kindly gifted by MSN laboratories, Hyderabad, India. The BSN was used as received. A stock standard solution containing $1 \mathrm{mg} / \mathrm{mL}$ of BSN was prepared in acetone $(\operatorname{method} \mathrm{A})$, methanol $(\operatorname{method} \mathrm{B})$, dichloromethane (method C) and diluent (method D). Working standard solution equivalent to $100 \mu \mathrm{g} / \mathrm{mL}$ (methods A \& B) and $250 \mu \mathrm{g} / \mathrm{mL}$ (method C) of BSN was obtained by appropriate dilution of stock solution by the respective solvents.

\section{General assay procedure} Method A (Spectrophotometry)

Into a series of $10 \mathrm{~mL}$ volumetric flasks, volumes $(0.2-3.0 \mathrm{~mL})$ of BSN standard solution $(100 \mu \mathrm{g} / \mathrm{mL})$ equivalent to $2-30 \mu \mathrm{g}$ of the drug were transferred. The volume in all the flasks was made up to $3 \mathrm{~mL}$ with acetone. To each flask, $1.5 \mathrm{~mL}$ of $5 \% \mathrm{AM}$ and $2 \mathrm{~mL}$ of $2 \mathrm{M} \mathrm{HCl}$ were added. The mixture was homogenized by shaking, immersed in a water bath at $60^{\circ} \mathrm{C}$ for $35 \mathrm{~min}$ and then cooled to room temperature. The mixture was diluted to volume with acetone. The absorbance of the blue colored chromogen was measured at $720 \mathrm{~nm}$ against a blank prepared similarly omitting the drug. The standard calibration curve was prepared to calculate the amount of the BSN in unknown samples.

\section{Method B (Spectrophotometry)}

Into a series of $10 \mathrm{~mL}$ volumetric flasks, volumes $(0.5-3.0 \mathrm{~mL})$ of BSN standard solution $(100 \mu \mathrm{g} / \mathrm{mL})$ equivalent to $5-30 \mu \mathrm{g}$ of the drug were transferred. The volume in all the flasks was made up to $3 \mathrm{~mL}$ with methanol. To each flask, $1.0 \mathrm{~mL}$ of $0.1 \%$ DNP was added and brought 
up to the volume with methanol. The absorbance of the yellow colored product formed at room temperature $\left(25 \pm 1{ }^{\circ} \mathrm{C}\right)$ was measured at $445 \mathrm{~nm}$ against the reagent blank prepared similarly omitting the drug. The standard calibration curve was prepared to calculate the amount of the BSN in unknown samples.

\section{Method C (Spectrophotometry)}

Into a series of $10 \mathrm{~mL}$ volumetric flasks, volumes $(0.1-2.0 \mathrm{~mL})$ of BSN standard solution $(250 \mu \mathrm{g} / \mathrm{mL})$ equivalent to $2.5-50 \mu \mathrm{g}$ of the drug were transferred. The volume in all the flasks was made up to $2 \mathrm{~mL}$ with dichloromethane. To each flask, $1.0 \mathrm{~mL}$ of $0.07 \%$ BCG was added and brought up to the volume with dichloromethane. The absorbance of the yellow colored product formed at room temperature $\left(25 \pm 1{ }^{\circ} \mathrm{C}\right)$ was measured at $420 \mathrm{~nm}$ against the reagent blank prepared similarly omitting the drug. The standard calibration curve was prepared to calculate the amount of the BSN in unknown samples.

\section{Method D (HPLC)}

A series of working standard solutions $(5,10,20,40,60,80$ and $100 \mu \mathrm{g} / \mathrm{mL} \mathrm{BSN})$ obtained by appropriate dilution of the stock standard solution with the mobile phase were taken. From each solution $20 \mu \mathrm{L}$ was injected into the HPLC column in triplicate. The mobile phase is pumped from the solvent reservoir to the column at a flow rate of $1 \mathrm{~mL} / \mathrm{min}$. The peaks were determined at $227 \mathrm{~nm}$. The average peak areas versus concentration of the BSN $(\mu \mathrm{g} / \mathrm{mL})$ were plotted. The concentration of BSN was quantified using the standard calibration curve.

\section{Procedure for the analysis of BSN in tablet dosage forms}

Ten tablets were weighed accurately and ground into a fine powder. An amount of powder equivalent to $100 \mathrm{mg}$ of BSN was weighed into a $100 \mathrm{~mL}$ volumetric flask, $50 \mathrm{~mL}$ of the acetone $(\operatorname{method} \mathrm{A})$ or methanol $(\operatorname{method} \mathrm{B})$ or dichloromethane $(\operatorname{method} \mathrm{C})$ or diluent solution (method D) was added and shaken thoroughly for about $10 \mathrm{~min}$, then the volume was diluted up to the mark with the respective solvents, mixed well and filtered using a quantitative filter paper (in case of methods A,B and C) or through $0.45 \mu \mathrm{m}$ membrane filter (in case of method D). The filtered solution was appropriately diluted with the respective solvents. Convenient aliquots were subjected to analysis by the procedures described under methods A, B, C \& D.

\section{Results and Discussion}

Method A (Spectrophotometry)

Ammonium molybdate (MoVI) has been used as oxidizing agent in the spectrophotometric estimation of compounds of pharmaceutical significance ${ }^{16-19}$. In acidic medium, AM (MoVI) is reduced to colored molybdenum blue (MoV) on treatment with reducing substances. The proposed method A is based on the oxidation of the BSN with AM (MoVI) in acidic medium, which was subsequently reduced to molybdenum blue (MoV). The MoV ion exhibited absorption maxima at $720 \mathrm{~nm}$ against the reagent blank (Figure 2).

\section{Method B (Spectrophotometry)}

2,4 Dinitrophenol has several applications as analytical reagent ${ }^{20-22}$, it has been used for the spectrophotometric determination of many drugs. The interaction of DNP with primary or secondary amine in organic solvent leads to the formation a yellow colored phenolate ion by proton transfer ${ }^{23}$, The proposed method B is based on the formation of an ion-pair complex as a result of a proton transfer from hydroxyl group of Lewis acid, DNP, to the secondary amino group of Lewis base, BSN (Figure 3). The resulted yellow colored ion- pair complex showed maximum absorbance at $445 \mathrm{~nm}$ against the reagent blank (Figure 4). 


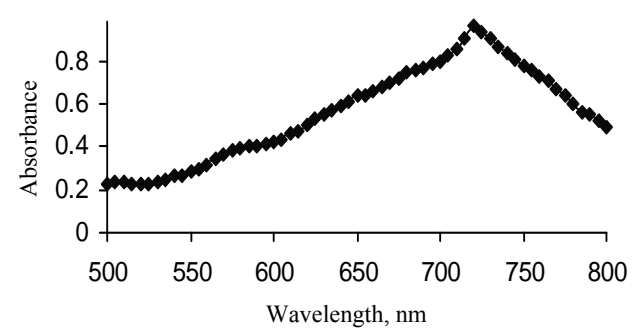

Figure 2. Absorption spectra of molybdenum blue (MoV) - method A<smiles>COc1ccccc1Oc1c(NS(=O)(=O)c2ccc(C(C)(C)C)cc2)nc(-c2ncccn2)nc1OCCO</smiles>

Bosentan

2,4 Dinitrophenol<smiles>COc1ccccc1Oc1c(NS(=O)(=O)c2ccc(C(C)(C)C)cc2)nc(-c2ncccn2)nc1OCCO</smiles>

Figure 3. Proposed reaction mechanism for the formation of BSN-DNP ion pair complex method B

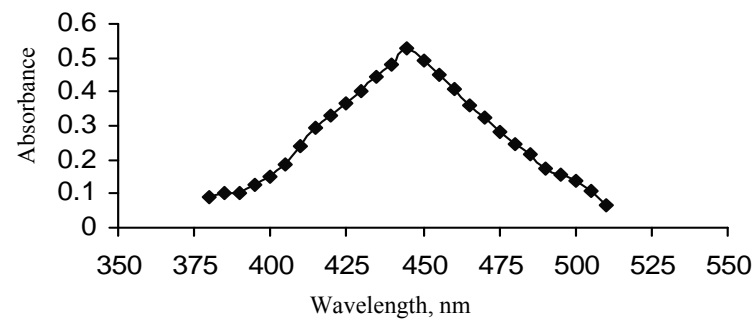

Figure 4. Absorption spectra of BSN-DNP ion pair complex - method B

\section{Method C (Spectrophotometry)}

The sulphophthalein dye, BCG, has been widely used in the assay of several drugs ${ }^{24-25}$, Being an anionic dye, BCG forms ion-pair complex with positively charged drugs. When a solution of BCG in dichloromethane is added to the BSN solution, a yellow colored product is produced instantaneously. The lactoid ring of the BCG opens to form a quinoidal anionic derivative. This derivative forms an ion-pair complex with protonated form of BSN (Figure 5). The yellow colored ion-pair complex exhibited absorption maxima at $420 \mathrm{~nm}$ against the reagent blank (Figure 6). 

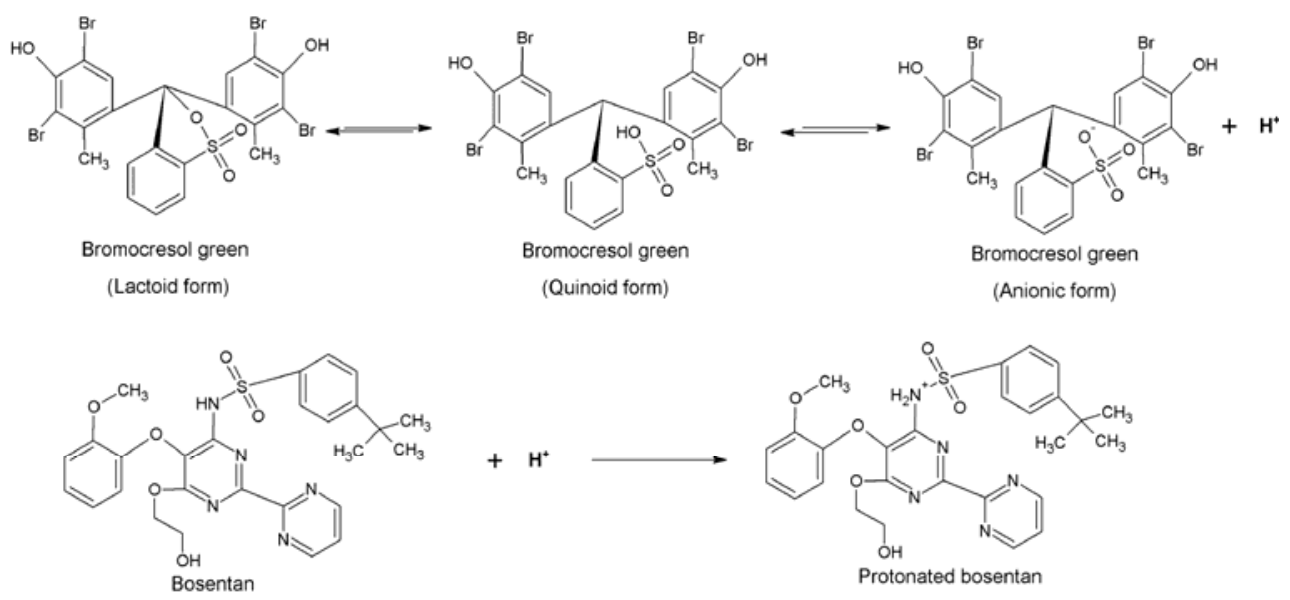

Bromocresol green (anionic form)
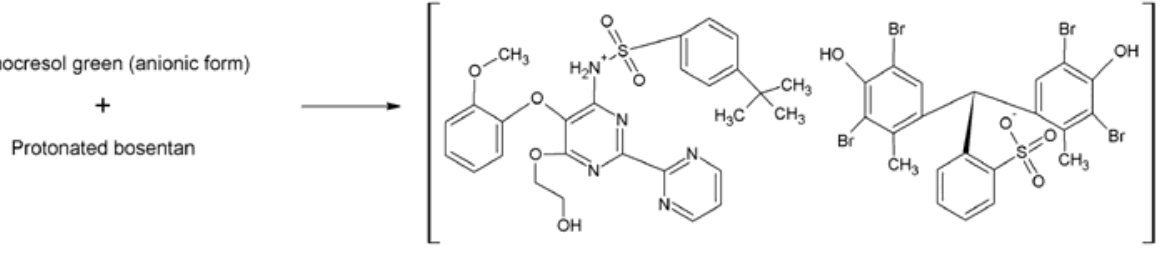

Yellow colored ion-pair complex

Figure 5. Proposed reaction mechanism for the formation of BSN-BCG ion pair complex method C

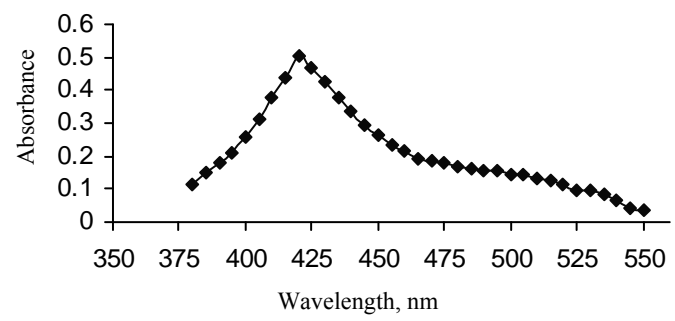

Figure 6. Absorption spectra of BSN-BCG ion pair complex - method C

\section{Optimization of experimental variables}

\section{Methods A, B and C (Spectrophotometry)}

The factors affecting reaction conditions (concentration of AM, acidity, solvent used for dilution, reaction time and temperature in method A; concentration of DNP and solvent used for dilution in method B; concentration of BCG and solvent used for dilution in method C) were evaluated by varying each variable in turn while keeping the others constant and observing the effect produced on the absorbance of the colored product. The optimum values of the variables were maintained throughout the experiment to quantify the concentration of BSN.

In method $\mathrm{A}$, the effect of volume of $5 \% \mathrm{AM}$ and $2 \mathrm{M} \mathrm{HCl}$ on the absorbance of the colored product was studied. The maximum absorbance was obtained with $1.5 \mathrm{~mL}$ of $5 \%$ $\mathrm{AM}$ and $2 \mathrm{~mL}$ of $2 \mathrm{M} \mathrm{HCl}$. The optimum time and temperature required for the formation of molybdenum blue (MoV) was 35 minutes at $60{ }^{\circ} \mathrm{C}$. 
In method $\mathrm{B}$, the color reaction was studied as a function of the concentration of DNP. The results indicated that the maximum color intensity was obtained with $1.0 \mathrm{~mL}$ of $0.1 \%$ DNP. The optimization experiments have revealed that $1.0 \mathrm{~mL}$ of $0.07 \% \mathrm{BCG}$ was sufficient for covering the broad range of Beer's law limit in method C.

The BSN was insoluble in water. In order to select an appropriate solvent, the reaction of BSN with AM (method A) or DNP (method B) or BCG (method C) was studied in different solvents like acetone, butanol, methanol, acetonitrile, chloroform and dichloromethane. It was found that acetone was the best solvent for dilution for method A as it gave the highest color intensity. In the case of method B, better results were achieved in methanol medium whereas dichloromethane was selected as the suitable solvent for method $\mathrm{C}$, yielding maximum absorbance.

\section{Method D (HPLC)}

For optimization of the chromatographic conditions and to obtain symmetrical peaks, various chromatographic conditions such as type of column, column temperature, composition of mobile phase, $\mathrm{pH}$ of the mobile phase, flow rate and detection wavelength were studied.

Two different analytical columns, Thermo Scientific C18 column $(250 \mathrm{~mm} \times 4.6 \mathrm{~mm}$ I.D., $5 \mu \mathrm{m}$ particle size) and Agilent C18 column $(150 \mathrm{~mm} \times 4.6 \mathrm{~mm}$ I.D., $5 \mu \mathrm{m}$ particle size), were tested initially. Highly symmetrical and sharp peaks with less retention time were obtained for Agilent C18 column, which was chosen for the determination process. The best peak shape along with the highest column efficiency was achieved, when the column is maintained at room temperature $\left(25 \pm 1{ }^{\circ} \mathrm{C}\right)$.

To investigate the appropriate wavelength for the determination of BSN, the solution of BSN was scanned by UV-Visible spectrophotometer. It was observed that the maximum absorbance of BSN was obtained at $227 \mathrm{~nm}$.

The ammonium acetate buffer with different $\mathrm{pH}$ (3-8) was tried. It was found that a sharp and symmetrical peak shape was observed at $\mathrm{pH} 4.5$ (adjusted with glacial acetic acid). Mobile phases consisting of methanol and ammonium acetate buffer ( $\mathrm{pH} 4.5)$ in different volumetric ratios were investigated. The best results were achieved by using a mixture of methanol and ammonium acetate buffer $(\mathrm{pH} 4.5)$ in the ratio of $60: 40 \mathrm{v} / \mathrm{v}$ as mobile phase. The mobile phase with different flow rates $(0.8-1.6 \mathrm{~mL} / \mathrm{min})$ was studied. At the flow rate $1 \mathrm{~mL} / \mathrm{min}$, symmetric and well retained peak was obtained.

Under the optimized chromatographic conditions highly symmetrical and sharp peak of BSN was obtained at retention time of 2.572 (Figure 7).

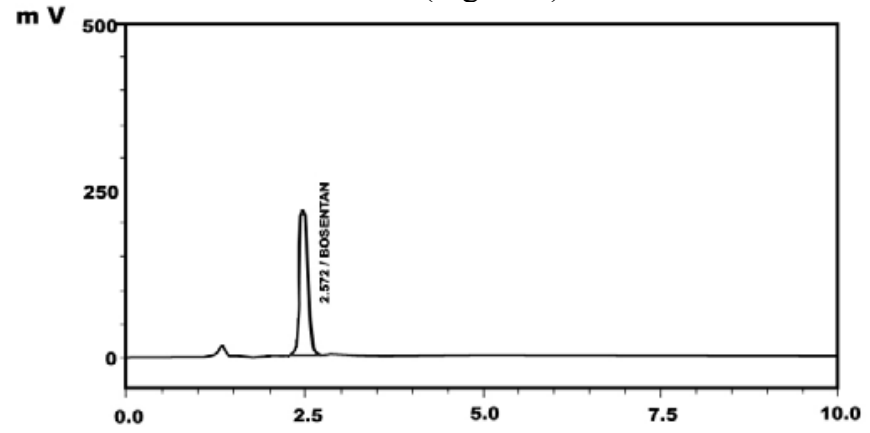

Figure 7. Chromatogram of pure BSN - method D 


\section{Method Validation}

\section{Linearity}

\section{Spectrophotometry}

After optimizing the experimental conditions, it was found that the relation between the absorbance and final concentration of BSN was linear over the range of 2-30 $\mu \mathrm{g} / \mathrm{mL}, 5-$ $30 \mu \mathrm{g} / \mathrm{mL}$ and $2.5-50 \mu \mathrm{g} / \mathrm{mL}$ for methods $\mathrm{A}, \mathrm{B}$ and $\mathrm{C}$, respectively. The linear regression analysis of the results gave the following equation:

Method A: $\mathrm{A}=0.0391 \mathrm{c}+0.0048\left(r^{2}=0.9980\right)$

Method B: $\mathrm{A}=0.014 \mathrm{c}-0.0048\left(r^{2}=0.9987\right)$

Method C: $\mathrm{A}=0.0095 \mathrm{c}-0.0004\left(r^{2}=0.9994\right)$

Where $\mathrm{A}=$ Absorbance; $\mathrm{c}=$ Concentration of $\mathrm{BSN}$ in $\mu \mathrm{g} / \mathrm{mL} ; r^{2}=$ Regression coefficient. The regression coefficient $(>0.99)$ values obtained, specify that there is a good correlation between absorbance and BSN concentration in all the proposed methods.

\section{HPLC}

The data from the calibration curve showed that the response of the BSN was linear in the studied concentration range $(5-100 \mu \mathrm{g} / \mathrm{mL})$. The regression equation of the line was $\mathrm{A}=$ $61367 \mathrm{c}+96711$ (where $\mathrm{A}=$ peak area and $\mathrm{c}=$ concentration of BSN in $\mu \mathrm{g} / \mathrm{mL}$ ). A very high correlation of 0.9988 obtained, demonstrates that there is a good linear relationship between peak area and concentration of BSN.

\section{Sensitivity}

Molar absorptivity, Sandell's sensitivity, limits of detection (LOD) and limits of quantification (LOQ) are calculated as per the current ICH guidelines ${ }^{26}$ to assess the sensitivity of the proposed methods. The results are summarized in Table 1 . These results point out the excellent sensitivity of the proposed methods.

Table 1. Sensitivity of the proposed methods

\begin{tabular}{lcccc}
\hline \multirow{2}{*}{ Parameter } & \multicolumn{4}{c}{ Method } \\
\cline { 2 - 5 } & $\mathrm{A}$ & $\mathrm{B}$ & $\mathrm{C}$ & $\mathrm{D}$ \\
\hline Molar absorbtivity, & $2.164 \times 10^{4}$ & $7.348 \times 10^{3}$ & $5.468 \times 10^{3}$ & - \\
L/mol/cm & & & & \\
Sandell's sensitivity, & 0.0263 & 0.0775 & 0.1041 & - \\
$\mu \mathrm{g} \mathrm{cm}-2$ & 0.043 & 0.121 & 0.310 & 0.145 \\
$\mathrm{LOD}, \mu \mathrm{g} / \mathrm{mL}$ & 0.130 & 0.366 & 0.939 & 0.439 \\
$\mathrm{LOQ}, \mu \mathrm{g} / \mathrm{mL}$ & &
\end{tabular}

\section{Precision and accuracy}

To establish the intra- \& inter-day precision and accuracy of the proposed methods, repeatability studies were performed. For intra-day studies, BSN solution at three different concentration levels (within linearity range) was analyzed by the proposed methods on the same day. These studies were also repeated on three consecutive days to verify the interday precision and accuracy. From the data obtained, concentration was calculated. The results were expressed as relative standard deviation and percent recovery. The results of intra- and inter-day studies are shown in Table 2. The low relative standard deviation values indicate good precision and high recovery values indicate good accuracy of the proposed methods. 
Table 2. Accuracy and precision of the proposed methods

\begin{tabular}{|c|c|c|c|c|c|c|c|c|}
\hline \multirow{3}{*}{ Method } & \multicolumn{4}{|c|}{ Intra-day analysis } & \multicolumn{4}{|c|}{ Inter-day analysis } \\
\hline & \multicolumn{2}{|c|}{$\mathrm{BSN}, \mu \mathrm{g} / \mathrm{mL}$} & \multirow{2}{*}{ \% RSD } & \multirow{2}{*}{$\begin{array}{c}\% \\
\text { Recovery }\end{array}$} & \multicolumn{2}{|c|}{$\mathrm{BSN}, \mu \mathrm{g} / \mathrm{mL}$} & \multirow{2}{*}{$\% \mathrm{RSD}$} & \multirow{2}{*}{$\begin{array}{c}\% \\
\text { Recovery }\end{array}$} \\
\hline & Taken & Found $^{*} \pm \mathrm{SD}$ & & & Taken & Found $^{*} \pm \mathrm{SD}$ & & \\
\hline \multirow{3}{*}{ A } & 3 & $3.004 \pm 0.020$ & 0.665 & 100.13 & 3 & $2.991 \pm 0.012$ & 0.401 & 99.70 \\
\hline & 16 & $15.989 \pm 0.014$ & 0.087 & 99.93 & 16 & $15.991 \pm 0.013$ & 0.081 & 99.94 \\
\hline & 28 & $28.020 \pm 0.011$ & 0.039 & 100.07 & 28 & $28.006 \pm 0.013$ & 0.046 & 100.02 \\
\hline \multirow{3}{*}{ B } & 5 & $4.972 \pm 0.043$ & 0.864 & 99.44 & 5 & $4.971 \pm 0.014$ & 0.046 & 99.42 \\
\hline & 20 & $19.949 \pm 0.077$ & 0.386 & 99.74 & 20 & $19.991 \pm 0.067$ & 0.335 & 99.95 \\
\hline & 28 & $27.975 \pm 0.037$ & 0.132 & 99.91 & 28 & $28.038 \pm 0.036$ & 0.128 & 100.13 \\
\hline \multirow{3}{*}{$C$} & 5 & $5.032 \pm 0.050$ & 0.993 & 100.64 & 5 & $5.047 \pm 0.016$ & 0.317 & 100.94 \\
\hline & 25 & $25.050 \pm 0.054$ & 0.215 & 100.20 & 25 & $25.216 \pm 0.087$ & 0.345 & 100.86 \\
\hline & 50 & $50.053 \pm 0.058$ & 0.115 & 100.10 & 50 & $50.107 \pm 0.094$ & 0.187 & 100.21 \\
\hline \multirow{3}{*}{ D } & 5 & $4.95 \pm 0.016$ & 0.323 & 99.00 & 5 & $4.98 \pm 0.022$ & 0.441 & 99.60 \\
\hline & 50 & $49.97 \pm 0.115$ & 0.230 & 99.94 & 50 & $50.04 \pm 0.166$ & 0.331 & 100.08 \\
\hline & 100 & $99.95 \pm 0.328$ & 0.328 & 99.95 & 100 & $100.03 \pm 0.419$ & 0.418 & 100.03 \\
\hline
\end{tabular}

*Average of five determinations

\section{Recovery studies}

Accuracy of the proposed methods was further evaluated by spiking the pure drug to the preanalyzed dosage form. The resulting solutions were once again analyzed by proposed methods. The percent recovery of BSN was then calculated using the corresponding calibration curve or regression equation. The data from recovery studies is shown in Table 3. Good recoveries were obtained, which is an indication of high accuracy of the proposed methods. The absence of interference from the tablet excipients also indicates the selectivity of the proposed methods.

Table 3. Recovery data of the proposed methods

\begin{tabular}{ccccc}
\hline \multirow{2}{*}{ Method } & \multicolumn{3}{c}{ Amount of BSN, mg } & \multirow{2}{*}{$\%$ Recovery } \\
\cline { 2 - 4 } & Tablet & Spiked & Found $^{*} \pm$ SD & \\
\hline \multirow{2}{*}{ A } & 62.5 & 31.25 & $93.72 \pm 0.569$ & 99.96 \\
& 125 & 62.5 & $187.59 \pm 0.082$ & 100.04 \\
B & 62.5 & 31.25 & $93.70 \pm 0.579$ & 99.94 \\
& 125 & 62.5 & $187.76 \pm 0.239$ & 100.13 \\
C & 62.5 & 31.25 & $93.78 \pm 0.571$ & 100.03 \\
& 125 & 62.5 & $187.73 \pm 0.215$ & 100.12 \\
D & 62.5 & 31.25 & $93.76 \pm 0.579$ & 100.01 \\
& 125 & 62.5 & $187.46 \pm 0.986$ & 99.97 \\
\hline
\end{tabular}

* Average of five determinations

\section{Robustness}

In order to ascertain the robustness of the proposed methods, minute deliberated changes were made in the following experimental conditions at two different concentration levels (method A - $3 \mu \mathrm{g} / \mathrm{mL}$ and $28 \mu \mathrm{g} / \mathrm{mL}$; method B - $5 \mu \mathrm{g} / \mathrm{mL}$ and $28 \mu \mathrm{g} / \mathrm{mL}$; method C - $5 \mu \mathrm{g} / \mathrm{mL}$ and $45 \mu \mathrm{g} / \mathrm{mL}$; method D - $5 \mu \mathrm{g} / \mathrm{mL}$ and $100 \mu \mathrm{g} / \mathrm{mL}$ ):

\section{Method A}

Volume of ammonium molybdate $(1.5 \pm 0.1 \mathrm{~mL})$; Volume of $2 \mathrm{M} \mathrm{HCl}(2.0 \pm 0.1 \mathrm{~mL})$; Temperature $\left(60 \pm 2{ }^{\circ} \mathrm{C}\right)$ and Reaction time $(35 \pm 2 \mathrm{~min})$ 


\section{Method B}

Volume of 2,4 dinitrophenol (1.0 $\pm 0.1 \mathrm{~mL})$

Method C

Volume of bromocresol green $(1.0 \pm 0.1 \mathrm{~mL})$

\section{Method D}

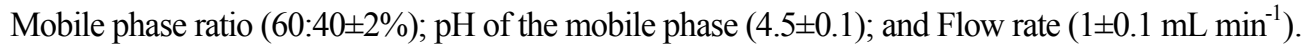
In the above-changed conditions, \%RSD is reasonably low $(<1 \%)$ for all the parameters of robustness which indicate that the proposed methods are robust for the quantification of BSN Table 4.

Table 4. Robustness of the proposed methods

\begin{tabular}{|c|c|c|c|c|}
\hline \multirow{2}{*}{ Parameter } & \multicolumn{2}{|c|}{ Amount of BSN, $\mu \mathrm{g} / \mathrm{mL}$} & \multirow{2}{*}{$\begin{array}{c}\% \\
\text { Recovery }\end{array}$} & \multirow{2}{*}{$\begin{array}{c}\% \\
\text { RSD }\end{array}$} \\
\hline & Taken & Found $^{*} \pm \mathrm{SD}$ & & \\
\hline \multicolumn{5}{|l|}{ Method A } \\
\hline Volume of AM & 3 & $2.997 \pm 0.016$ & 99.90 & 0.533 \\
\hline$(1.5 \pm 0.1 \mathrm{~mL})$ & 28 & $28.002 \pm 0.019$ & 100.00 & 0.067 \\
\hline Volume of $2 \mathrm{M} \mathrm{HCl}$ & 3 & $2.998 \pm 0.014$ & 99.93 & 0.466 \\
\hline$(2.0 \pm 0.1 \mathrm{~mL})$ & 28 & $28.031 \pm 0.039$ & 100.11 & 0.139 \\
\hline Temperature & 3 & $2.999 \pm 0.011$ & 99.96 & 0.366 \\
\hline$\left(60+2{ }^{\circ} \mathrm{C}\right)$ & 28 & $28.029 \pm 0.041$ & 100.10 & 0.146 \\
\hline Reaction time & 3 & $3.006 \pm 0.011$ & 100.20 & 0.365 \\
\hline$(35+2 \min )$ & 28 & $27.998 \pm 0.047$ & 99.99 & 0.167 \\
\hline \multicolumn{5}{|l|}{ Method B } \\
\hline Volume of DNP & 5 & $5.039 \pm 0.012$ & 100.78 & 0.238 \\
\hline$(1.0 \pm 0.1 \mathrm{~mL})$ & 28 & $28.028 \pm 0.052$ & 100.10 & 0.185 \\
\hline \multicolumn{5}{|l|}{ Method C } \\
\hline Volume of BCG & 5 & $5.060 \pm 0.016$ & 101.20 & 0.316 \\
\hline$(1.0 \pm 0.1 \mathrm{~mL})$ & 45 & $50.101 \pm 0.099$ & 100.20 & 0.197 \\
\hline \multicolumn{5}{|l|}{ Method D } \\
\hline Mobile phase & 5 & $5.01 \pm 0.028$ & 100.02 & 0.558 \\
\hline$(60: 40 \pm 2 \%)$ & 100 & $99.98 \pm 0.169$ & 99.98 & 0.169 \\
\hline $\mathrm{pH}$ of the mobile & 5 & $4.98 \pm 0.018$ & 99.60 & 0.361 \\
\hline phase $(4.5 \pm 0.1)$ & 100 & $99.93 \pm 0.902$ & 99.93 & 0.902 \\
\hline Flow rate & 5 & $4.98 \pm 0.019$ & 99.60 & 0.381 \\
\hline$(1 \pm 0.1 \mathrm{~mL} / \mathrm{min})$ & 100 & $99.79 \pm 0.892$ & 99.79 & 0.893 \\
\hline
\end{tabular}

\section{Application to tablet dosage forms}

The proposed methods were successfully applied to the analysis of BSN in their marketed tablet dosage forms (Bosentas tablets, Cipla Pvt. Ltd., Hyderabad, India). The results are shown in Table 5. The results obtained were satisfactory, accurate, and precise as indicated by the good recovery and low standard deviation values. There was no interference of excipients generally found in tablet dosage forms. 
Table 5. Assay of bosentan in tablet dosage forms

\begin{tabular}{ccc}
\hline Method & $\begin{array}{c}\text { Labeled } \\
\text { claim, mg }\end{array}$ & Found $(\mathrm{mg}) \pm \mathrm{SD}^{*} ; \% \mathrm{R} ; \% \mathrm{RSD}$ \\
\hline \multirow{2}{*}{$\mathrm{A}$} & 62.5 & $62.49 \pm 0.044 ; 99.98 ; 0.070$ \\
& 125.0 & $125.06 \pm 0.054 ; 100.04 ; 0.043$ \\
$\mathrm{~B}$ & 62.5 & $62.53 \pm 0.086 ; 100.04 ; 0.137$ \\
& 125.0 & $125.06 \pm 0.120 ; 100.04 ; 0.096$ \\
$\mathrm{C}$ & 62.5 & $62.55 \pm 0.076 ; 100.08 ; 0.121$ \\
& 125.0 & $125.160 \pm 0.137 ; 100.12 ; 0.109$ \\
$\mathrm{D}$ & 62.5 & $61.496 \pm 0.601 ; 99.90 ; 0.977$ \\
& 125.0 & $124.96 \pm 0.986 ; 99.96 ; 0.789$ \\
\hline
\end{tabular}

\section{Conclusion}

*Average of five determinations; $\% R$ - percentage recovery

Three spectrophotometric methods (A, B and C) and one HPLC method (D) for the quantification of bosentan in pure and in its pharmaceutical dosage forms was developed. The methods were validated as per the International Conference on Harmonization guidelines. The proposed methods are sensitive and have broad linearity range, good accuracy and precision. The methods (A, B, C and D) can be used for routine analysis of bosentan in pharmaceutical dosage forms.

\section{Acknowledgement}

One of the authors, P. Lavudu, expresses his gratitude to the management of Vishnu Institute of Pharmaceutical Education \& Research, Narsapur and Principal, University College of Pharmaceutical Sciences, Acharya Nagarjuna University, Guntur for providing research facilities.

\section{References}

1. Raja S G and Dreyfus G D, Ann Card Anaesth., 2008, 11(1), 6-14; DOI:10.4103/0971-9784.38443

2. Gabbay E F J and McNeil K, Vasc Health Risk Manag., 2007, 3(6), 887-900.

3. Roux S, Breu V, Ertel S I and Clozel M, J Mol Med., 1999, 77(4), 364-376; DOI:10.1007/s001090050363

4. Dingemans J and VanGiersbergen P L, Clin Pharmacokinet., 2004, 43(15), 10891115; DOI:10.2165/00003088-200443150-00003

5. Annapurna M M, Bisht Kumar S P S and Narendra B V V R V R, Int J Comp Pharm., 2011, 2(1), 1-4.

6. Ashok Kumar A, Anil Kumar A and Sankar D G, Int J Pharm Biol Sci., 2011, 2(2), 225-230.

7. Kumar D, Sreenivas S A, Samal H B, Dey S and Priyanka Y, J Pharm Res., 2011, 4(6), 1713-1715.

8. $\quad$ Narendra A, Deepika D and Annapurna M M, J Chem., 2012, 9(2), 700-704; DOI:10.1155/2012/359745

9. Khan M A, Sinha S, Todkar M, Parashar V and Swamy K R, Am J Sci Ind Res., 2012, 3(2), 69-80; DOI:10.5251/ajsir.2012.3.2.69.80

10. Jadhav S A, Landge S B, Jadhav S L, Niphade N C, Bembalkar S R and Mathad V T, Chromatogr Res Int., 2011, 13, 61-66; DOI:10.4061/2011/929876 
11. Lausecker B and Hopfgartner G, J Chromatogr A, 1995, 712(1), 75-83;

DOI:10.1016/0021-9673(95)00331-G

12. Lausecker B, Hess B, Fischer G, MuellerM and Hopfgartner G, J Chromatogr B Biomed Sci., 2000, 749(1), 67-83; DOI:10.1016/S0378-4347(00)00386-8

13. Muralidharan S and Kumar J R, Am J Anal Che., 2012, 3, 715-718.

14. Reddy T K, Younus M d, Reddy Y R, Kumar GA and Sravan S, Int J Pharm Tech., 2010, 2(3), 577-587.

15. Rao T N, Patrudu T B, Raghubabu K, Nagachandrudu S, Sreenivasulu D and Reddy E G, Am J Pharm Tech Res., 2012, 2(5), 391-398.

16. Júniora L H M, Sousaa R A, Filhoa O F, Moraesa F C and Teixeira M F S, Anal Lett., 2005, 38(14), 2315-2326; DOI:10.1080/15265160500316351

17. Rahman N and Azmi A S N, Acta Biochim Pol., 2005, 52(4), 915-922.

18. Mumtaz A, Sattar A A, Nazir R and Naseem A, Pak J Pharm Sci., 2013, 26(1), 169-173.

19. Agrawal Y K and Majumdar F D, Anal Lett., 1995, 28(9), 1619-1627; DOI:10.1080/00032719508002769

20. Omar M A, Nagy D M, Hammad and Aly M A A A, J Pharm Sci., 2013, 3(3), 151-161.

21. Sameer A, Abdulrahman M and Basavaiah K, Int J Anal Chem., 2011, 2(5), 178-184.

22. Prashanth K N and Basavaiah K, Acta Pol Pharm., 2012, 69(2), 213-23.

23. Saito G and Matsunaga Y, Chem Soc Japan, 1971, 44(12), 3328-3335.

24. Rahman N, Ahmad Khan N and Hejaz Azmi S N, Farmaco, 2004, 59(1), 47-54; DOI:10.1016/j.farmac.2003.10.001

25. El-Didamony A M, Arch Pharm., 2005, 338(4), 190-197.

26. Validation of Analytical Procedures; Methodology, International Conference on Harmonization (ICH), Text and Methodology Q2(R 1), Complementary Guideline on Methodology dated 06 November 1996, incorporated in November 2005, London. 